(C) 2009 Plant Management Network.

Accepted for publication 29 June 2009. Published 7 August 2009.

\title{
Pathogenicity of Native Entomopathogenic Fungus Nomuraea rileyi Against Spodoptera litura
}

\author{
Mahesh S. Padanad, Department of Biology, Texas A\&M University, \\ TAMU-3258, College Station, TX 77843 USA (previous address, \\ Institute of Agri Biotechnology, University of Agricultural Sciences, \\ Dharwad, Karnataka- 580 005, India); and P. U. Krishnaraj, \\ Institute of Agri Biotechnology, University of Agricultural Sciences, \\ Dharwad Karnataka 580 005, India
}

Corresponding author: Mahesh S. Padanad. mpadanad@mail.bio.tamu.edu

Padanad, M. S., and Krishnaraj, P. U. 2009. Pathogenicity of native entomopathogenic fungus Nomuraea rileyi against Spodoptera litura. Online. Plant Health Progress doi:10.1094/PHP-2009-0807-01-RS.

\begin{abstract}
The entomopathogenic fungus Nomuraea rileyi was isolated from Spodoptera litura and Helicoverpa armigera insect cadavers collected from different sampling sites. Pathogenicity of ten $\mathrm{N}$. rileyi isolates against Spodoptera litura was studied by exposing third instars to topical application of a spore concentration of $10^{8}$ conidia/ml. All ten isolates of $\mathrm{N}$ rileyi were active against third instars of S. litura, resulting in 85 to $97 \%$ mortality. However, there were statistically no significant differences among the isolates with respect to the pathogenicity levels. Median lethal time $\left(\mathrm{LT}_{50}\right)$ values of $\mathrm{N}$. rileyi isolates against third instars of $\mathrm{S}$. litura ranged from 5.5 to 6.6 days, which were not statistically different. This strongly suggests that the isolates from different geographical locations are equally pathogenic against S. litura.

\section{I ntroduction}

Spodoptera litura Fabricius is a major pest of subtropical and tropical agricultural crops. Control relies mainly on the use of chemical insecticides including carbamates, pyrethroids, and organophosphates (18). Frequent use of these insecticides poses increasing problems for human health and the environment. Moreover, certain insects have developed resistance to some of these insecticides (8). The reduced effectiveness of insecticides has resulted in an increase in the number of applications and the doses for desired level of control (22). Consequently, there is renewed interest in utilizing biological agents such as bacteria, viruses, and fungi for control of insect pests. These biological agents including entomopathogenic fungi can provide an alternative and more environmentally friendly approach for the control of pests. Fungal diseases are known to cause insect mortality naturally $(10,25,33)$.

Entomopathogenic fungi are potential agents for pest control due to their specificity, mode of action and ease of application. This has promoted the evaluation of the entomopathogenic fungi as biocontrol agents in many countries.

Unlike bacteria or viruses, fungi infect insects by breaching the host cuticle. The insecticidal activity Nomuraea rileyi (Farlow) Samson to lepidopteran pests was reviewed by Ignoffo (11), and he concluded that the fungus was a candidate for further development as a microbial insecticide. A recent study on the pathogenesis of $\mathrm{N}$. rileyi against $\mathrm{S}$. litura showed that the infection process starts with adhesion of conidia on the insect cuticle (27). The germ tube penetrates through the cuticle, causes lysis of endocutilce, followed by development of hyphal bodies in the hemocoel which convert to invasive mycelia and causes death of the host. At the end of the infection cycle, mycelia
\end{abstract}


emerge from the cuticle and produces conidiophores (27). Also, N. rileyi secretes a proteinaceous substance inhibiting larval molt and metamorphosis (16). Entomopathogenic fungi also possess added advantage over other microbial control agents as they are capable of attacking all developmental stages of insects including pupal stages $(1,6)$. Most importantly, these entomopathogenic fungi are the principal pathogens on sucking pests since these hosts cannot ingest other pathogens like bacteria or viruses that infect through gut wall. Apart from this, virtually all insect orders are susceptible to fungal diseases. However, of the 700 species of entomopathogenic fungi currently known, only ten species have been are presently being developed for biocontrol (24). The full potential of entomopathogenic fungi has not been approached. However, previous studies indicate that the insect mycopathogen N. rileyi a dimorphic hypomycete causes fungal epizootics in population of several noctuid pests $(14,28,31)$. Moreover, previous bioassays have shown that $\mathrm{N}$. rileyi isolates from different geographical locations and different hosts vary in their virulence and specificity $(3,12,30,34)$. However, the virulence of entomopathogenic fungi is affected by environmental factors such as temperature, humidity, light, and solar radiation. The optimum temperature for conidia to germinate and penetrate into noctuid insect body for N. rileyi is 20 to $30^{\circ} \mathrm{C}(7,29)$. Also, the optimum humidity for conidial germination, infection and sporulation is 95 to $100 \%$ (29). Therefore, it is important to identify potential entomopathogenic fungal isolates which further can be exploited as mycoinsecticide for specific geographic locations. In this paper, our main objective was to study the insecticidal activity of $\mathrm{N}$. rileyi isolates obtained from different geographic locations against S. litura. Thus, the efficient isolates can be exploited as myco-insecticide for the control of S. litura which is a major pest against many vegetable and commercial crops like cabbage, okra, cotton, tobacco, soybean, and tomato in these specific geographic locations.

I solation and I dentification of $\mathrm{N}$. rileyi I solates

N. rileyi was isolated from S. litura and Helicoverpa armigera (Hübner) cadavers collected from different geographic locations based on the symptoms of infection in the cadavers at the Institute of Agri Biotechnology, University of Agricultural Sciences, Dharwad, which is situated in the northern transitional zone of Karnataka State, India. Additionally, two isolates were available from other geographic locations for this study. The host insects, collection locations, isolate names, and geographical coordinates are listed in Table 1. The dead larvae collected from the fields were surface sterilized by immersing in $0.1 \%$ $\mathrm{HgCl}_{2}$ for $1 \mathrm{~min}$ followed by rinsing in three changes of sterile water. The surface sterilized, diseased specimens were cut in a sterile watch glass and a small portion of the infected tissue was transferred to a sterile culture plate containing Saborauds Maltose Agar Media fortified with 1\% yeast extract (SMAY) (2). The plates were incubated at $28^{\circ} \mathrm{C}$ and the colonies that came up were further purified by repeated subculture on SMAY media. The isolates that came up on the SMAY medium were identified as N. rileyi by microscopic examination according to the out-lines given by Samson et al. (1988) (26). 
Table 1. Geographical Isolates of N. rileyi used in this study.

\begin{tabular}{|c|c|c|c|c|}
\hline $\begin{array}{l}\text { SI. } \\
\text { no. }\end{array}$ & \begin{tabular}{|l} 
I solate \\
name
\end{tabular} & $\begin{array}{l}\text { Location of } \\
\text { collection }\end{array}$ & \begin{tabular}{|l|} 
Host \\
insect
\end{tabular} & $\begin{array}{l}\text { Geographical } \\
\text { coordinates }\end{array}$ \\
\hline 1 & NR-A & Arabhavi & S. litura & $16^{\circ} 12^{\prime} 0^{\prime \prime N}, 74^{\circ} 54^{\prime} 0^{\prime \prime E}$ \\
\hline 2 & NR-BL & Bailhongal & S. litura & $15^{\circ} 49^{\prime} 1.2^{\prime \prime N}, 74^{\circ} 52^{\prime} 1.2^{\prime \prime E}$ \\
\hline 3 & NR-DH & Devihosur & S. litura & $14^{\circ} 47^{\prime} 8.7^{\prime \prime N}, 75^{\circ} 20^{\prime} 0.74^{\prime \prime E}$ \\
\hline 4 & NR-D & Dharwad & S. litura & $15^{\circ} 28^{\prime} 0^{\prime \prime} \mathrm{N}, 75^{\circ} 1^{\prime} \mathrm{O}^{\prime \prime} \mathrm{E}$ \\
\hline 5 & NR-S & Siruguppa & S. litura & $15^{\circ} 37^{\prime} 48^{\prime \prime} N, 76^{\circ} 54^{\prime} 0^{\prime \prime E}$ \\
\hline 6 & NR-B ${ }^{X}$ & Bangalore & H. armigera & $12^{\circ} 58^{\prime} 0^{\prime \prime N}, 77^{\circ} 34^{\prime} 0^{\prime \prime E}$ \\
\hline 7 & NR-HB & Hirebagewadi & H. armigera & $16^{\circ} 17^{\prime} 24^{\prime \prime} N, 74^{\circ} 36^{\prime} 0^{\prime \prime E}$ \\
\hline 8 & NR- $H^{x}$ & Hyderabad & H. armigera & $17^{\circ} 22^{\prime} 31^{\prime \prime} \mathrm{N}, 78^{\circ} 28^{\prime} 28^{\prime \prime} \mathrm{E}$ \\
\hline 9 & NR-N & Nalavadi & H. armigera & $15^{\circ} 8^{\prime} 0^{\prime \prime} \mathrm{N}, 75^{\circ} 3^{\prime} 0^{\prime \prime} \mathrm{E}$ \\
\hline 10 & NR-R & Ron & H. armigera & $15^{\circ} 40^{\prime} 12^{\prime \prime} \mathrm{N}, 7543^{\prime} 48^{\prime \prime E}$ \\
\hline
\end{tabular}

$\mathrm{x}$ Isolates available for study from other geographic locations.

Isolation of the fungus on the SMAY medium yielded ten N. rileyi isolates. The microscopic examination revealed that the vegetative hyphae of N. rileyi appeared smooth septate, hyaline and conidiophores were erect and septate. Branches formed near a septum were developed in whorls each giving rise to 2 to 4 phialides. Conidia were single smooth ellipsoidal as shown in Figure 1. All the $\mathrm{N}$. rileyi isolates sporulated on SMAY media after 7 days of incubation as shown in Figure 2.

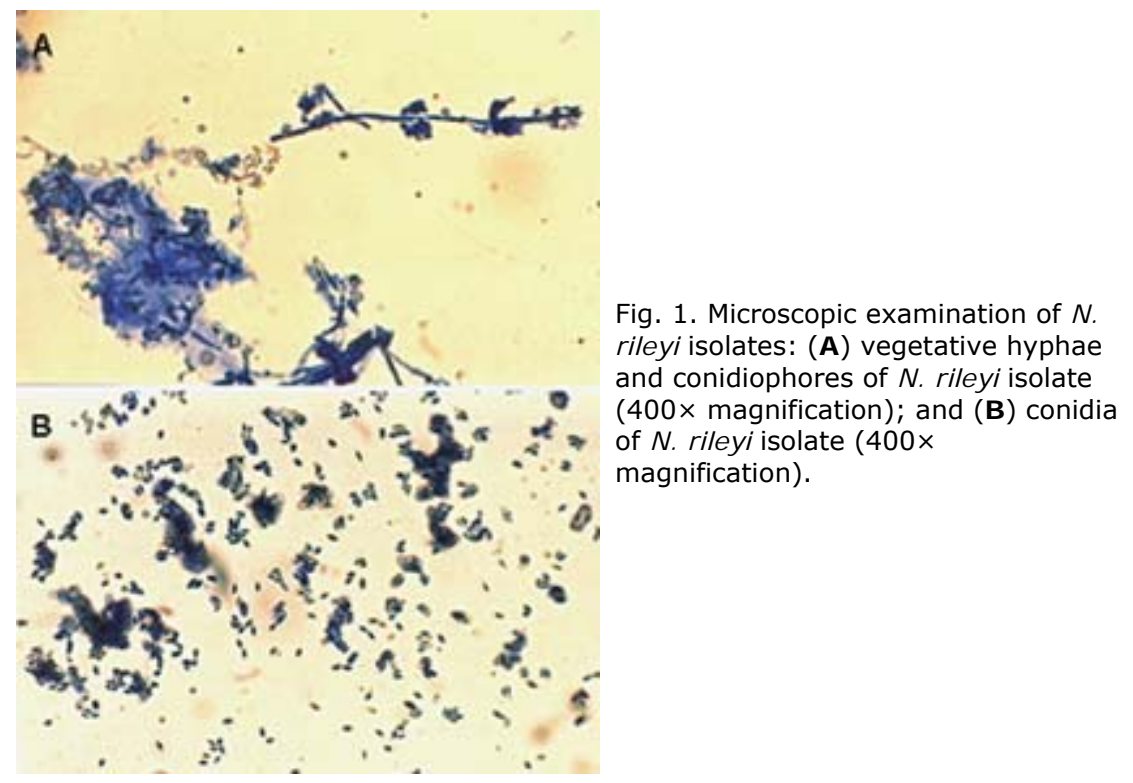




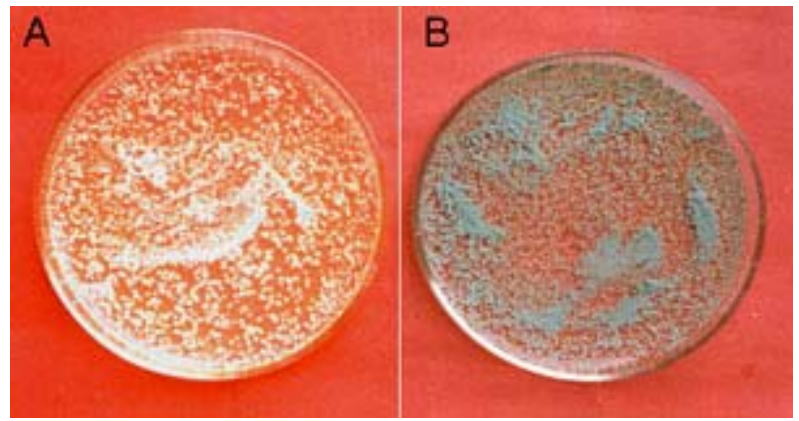

Fig. 2. In vitro growth of $\mathrm{N}$. rileyi on SMAY medium:

(A) growth of fungal hyphae (white in color); and

(B) spore production (green in color). Note the fungal vegetative growth in panel A (white) and sporulation in panel B (green).

\section{Preparation of Fungal Culture of N. rileyi I solates}

SMAY media was used for the multiplication of the fungus as well as spores. The cultured plates were incubated at $28^{\circ} \mathrm{C}$ for 7 to 10 days. Spores obtained on the SMAY media for the 10 isolates were screened for their insecticidal activity against third instars of S. litura. The fungal spores from SMAY plates were mixed with distilled water and $0.02 \%$ Tween-8o to produce the spore suspension. The number of conidia was determined with a Neubauer haemocytometer and a compound microscope. Finally, through serial dilution method spore suspensions containing $1 \times 10^{8}$ conidia/ml were obtained for the 10 individual isolates. The S. litura culture that was used for the bioassays was raised from field collected larvae and maintained under laboratory conditions in the Department of Entomology at University of Agricultural Sciences, Dharwad.

\section{Bioassays of $\mathbf{N}$. rileyi I solates}

Insecticidal activity of $\mathrm{N}$. rileyi isolates to S. litura was studied through larval bioassays. $500 \mu \mathrm{l}$ of spore suspension of $1 \times 10^{8}$ conidia $/ \mathrm{ml}$ of all the 10 isolates was topically applied on dorsal side of third instars with a small fine painting brush. They were fed with fresh castor leaves. Three replicates of 20 larvae were tested. Controls consisted of larvae applied with $500 \mu \mathrm{l}$ of distilled water and $0.02 \%$ Tween-80 solution. The number of dead larvae was recorded on the fifth day of spore inoculation and finally the percent mortality for each of the isolates was computed. The data were subjected to statistical analysis of variance using SAS OnlineDoc 9.1.3. (SAS Institute Inc., Cary, NC) and mean separation was carried out using DMRT (Duncan's Multiple Range Tests) to find significant difference among the isolates. Median lethal time $\left(\mathrm{LT}_{50}\right)$ was estimated using ProcLifeReg procedure and data were fitted to a Weibull distribution (SAS OnlineDoc 9.1.3). The differences in pathogenicity and $\mathrm{LT}_{50}$ among N. rileyi isolates against S. litura were compared using the Fisher's least significant difference test $(\alpha \leq 0.05)$.

Pathogenicity Levels of $\mathbf{N}$. rileyi I solates Against S. litura

All ten isolates of N. rileyi were pathogenic against S. litura. The mortality of S. litura, topically applied with the spore suspension is shown in Table 2, Table 3 , and Figure 3. Median lethal time ( $\mathrm{LT}_{50}$ in days) values of N. rileyi isolates against third instars of S. litura are shown in Table 4 and Table 5. 
Table 2. Effect of different $\mathrm{N}$. rileyi isolates of S.litura origin on the mortality of third instars of S. litura. ${ }^{x}$

\begin{tabular}{|l|l|c|c|c|c|c|c|}
\hline \multirow{2}{*}{$\begin{array}{l}\text { SI. } \\
\text { no. }\end{array}$} & \multirow{2}{*}{ I solates } & \multicolumn{7}{|c|}{$\begin{array}{c}\text { Percent mortality at indicated } \\
\text { days after spore inoculation }\end{array}$} \\
\cline { 3 - 8 } & $\mathbf{5}$ & $\mathbf{6}$ & $\mathbf{7}$ & $\mathbf{8}$ & $\mathbf{9}$ & $\mathbf{1 0}$ \\
\hline 1 & NR-A & $45.0 \mathrm{ab}$ & $56.7 \mathrm{ab}$ & $73.3 \mathrm{bc}$ & 83.3 & 91.7 & 91.7 \\
\hline 2 & NR-BL & $51.7 \mathrm{a}$ & $61.7 \mathrm{ab}$ & $70.0 \mathrm{bc}$ & 83.3 & 88.3 & 95.0 \\
\hline 3 & NR-DH & $46.7 \mathrm{a}$ & $60.0 \mathrm{ab}$ & $78.3 \mathrm{ab}$ & 86.7 & 90.0 & 93.3 \\
\hline 4 & NR-D & $53.3 \mathrm{a}$ & $75.0 \mathrm{a}$ & $86.7 \mathrm{a}$ & 91.7 & 96.7 & 96.7 \\
\hline 5 & NR-S & $33.3 \mathrm{~b}$ & $48.3 \mathrm{~b}$ & $65.0 \mathrm{c}$ & 78.3 & 85.0 & 88.3 \\
\hline
\end{tabular}

$x$ Conidial suspension: $1 \times 10^{8}$ conidia/ml.

$y$ Means followed by the same alphabet within the same column are not significantly different ( $P \leq 0.05)$ by Duncan's multiple range test.

Table 3. Effect of different $\mathrm{N}$. rileyi isolates of $\mathrm{H}$. armigera origin on the mortality of third instars of S. litura. ${ }^{x}$

\begin{tabular}{|l|l|c|c|c|c|c|c|}
\hline \multirow{2}{*}{$\begin{array}{l}\text { SI. } \\
\text { no. }\end{array}$} & \multirow{2}{*}{ I solates } & \multicolumn{6}{|c|}{$\begin{array}{c}\text { Percent mortality at indicated } \\
\text { days after spore inoculation }\end{array}$} \\
\cline { 3 - 8 } & $\mathbf{5}$ & $\mathbf{6}$ & $\mathbf{7}$ & $\mathbf{8}$ & $\mathbf{9}$ & $\mathbf{1 0}$ \\
\hline 1 & NR-B & 33.3 & 53.3 & 66.7 & 78.3 & 81.7 & 85.0 \\
\hline 2 & NR-HB & 38.3 & 48.3 & 61.7 & 73.3 & 86.7 & 91.7 \\
\hline 3 & NR-H & 38.3 & 43.3 & 58.3 & 75.0 & 90.0 & 90.0 \\
\hline 4 & NR-N & 31.7 & 50.0 & 71.7 & 78.3 & 85.0 & 86.7 \\
\hline 5 & NR-R & 45.0 & 56.7 & 66.7 & 86.7 & 93.3 & 93.3 \\
\hline
\end{tabular}

$\mathrm{x}$ Conidial suspension: $1 \times 10^{8}$ conidia $/ \mathrm{ml}$.

Table 4. $\mathrm{LT}_{50}$ values of $\mathrm{N}$. rileyi isolates of $\mathrm{S}$. litura origin on mortality of third instars of S. litura. $x$

\begin{tabular}{|l|l|c|c|c|}
\hline \multirow{2}{*}{$\begin{array}{l}\text { SI. } \\
\text { no. }\end{array}$} & \multirow{2}{*}{ I solates } & LT $_{\mathbf{5 0}}$ (days) $\mathbf{\text { SD }}$ & \multicolumn{2}{|c|}{$\mathbf{9 5 \% \text { confidence limits }}$} \\
\cline { 4 - 5 } & NR-A & $6.1 \pm 0.48$ & Lower limit & Upper limit \\
\hline 2 & NR-BL & $6.0 \pm 0.47$ & 5.21 & 7.15 \\
\hline 3 & NR-DH & $5.9 \pm 0.48$ & 5.15 & 7.02 \\
\hline 4 & NR-D & $5.5 \pm 0.38$ & 5.06 & 6.94 \\
\hline 5 & NR-S & $6.5 \pm 0.54$ & 4.80 & 6.29 \\
\hline
\end{tabular}

x Conidial suspension: $1 \times 10^{8}$ conidia/ml.

Table 5. $\mathrm{LT}_{50}$ values of $\mathrm{N}$. rileyi isolates of $\mathrm{H}$. armigera origin on mortality of third instars of S. litura. $x$

\begin{tabular}{|l|l|c|c|c|}
\hline \multirow{2}{*}{$\begin{array}{l}\text { SI. } \\
\text { no. }\end{array}$} & \multirow{2}{*}{ I solates } & LT $_{\mathbf{5 0}}$ (days) $\mathbf{\text { SD }}$ & \multicolumn{2}{|c|}{$\mathbf{9 5 \%}$ confidence limits } \\
\cline { 4 - 5 } & NR-B & $6.6 \pm 0.6$ & Lower limit & Upper limit \\
\hline 2 & NR-HB & $6.5 \pm 0.52$ & 5.52 & 7.89 \\
\hline 3 & NR-H & $6.6 \pm 0.48$ & 5.59 & 7.63 \\
\hline 4 & NR-N & $6.5 \pm 0.56$ & 5.13 & 7.02 \\
\hline 5 & NR-R & $6.1 \pm 0.46$ & 5.51 & 7.69 \\
\hline
\end{tabular}

x Conidial suspension: $1 \times 10^{8}$ conidia $/ \mathrm{ml}$. 


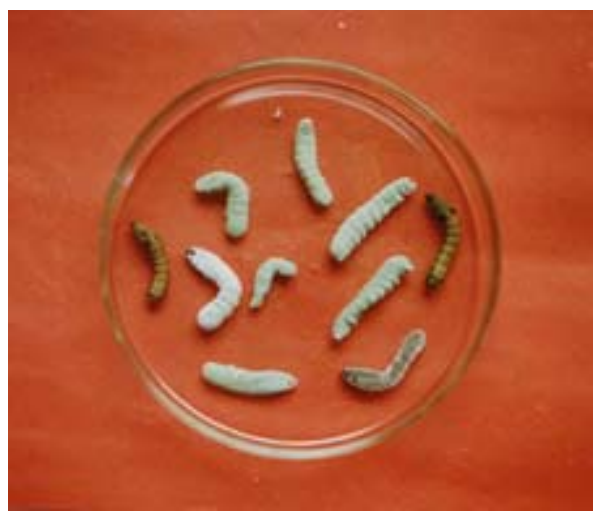

Fig. 3. The mortality of S. litura topically applied with $\mathrm{N}$. rileyi spores. Note the larvae at different stages of infection and mortality.

Bioassays of N. rileyi isolates of S. litura origin against S. litura showed that the Dharwad and Devihosur were the best in terms of optimum larval mortality of 78.3 and $86.7 \%$, respectively, within 7 days after spore inoculation (Table 2). This is similar to the observation made by other researchers that isolates from different geographic locations vary in their virulence and optimum larval mortality (34). However, there were no significant differences among the isolates in terms of efficacy from 8 to 10 days after spore inoculation. A similar level of mortality with different geographical isolates of N. rileyi has been reported (34). Initial mortality was observed at 5 days after treatment (Table 2). The median lethal time $\left(\mathrm{LT}_{50}\right)$ values ranged from 5.5 to 6.5 days among $\mathrm{N}$. rileyi isolates of S. litura origin (Table 4), which were not statistically different. However, geographical isolate from Dharwad location showed high parthogenicity against $\mathrm{S}$. litura with a $\mathrm{LT}_{50}$ (confidence interval) value of 5.5 days (4.8 to 6.29). This is consistent with observations made by other authors regarding $\mathrm{LT}_{50}$ values of $\mathrm{N}$. rileyi isolates against $\mathrm{S}$. litura and other lepidopteran pests $(4,19,28,29)$.

In case of larval bioassays with $\mathrm{N}$. rileyi isolates of $\mathrm{H}$. armigera origin, all isolates showed similar optimum larval mortality ( 73.3 to $86.7 \%$ ) within 8 days after spore inoculation (Table 3). However, there were no statistical significant differences among the isolates in terms of efficacy against $\mathrm{S}$. litura from 5 days itself after spore inoculation (Table 3 ). The $\mathrm{LT}_{50}$ values ranged from 6.1 to 6.6 days among $\mathrm{N}$. rileyi isolates of $\mathrm{H}$. armigera origin (Table 5), which were not statistically different. However, the geographical isolate from the Ron location showed a high pathogenicity against $\mathrm{S}$. litura with a $\mathrm{LT}_{50}$ (confidence interval) value of 6.1 days (5.24 to 7.08). This is consistent with the observations made by other authors $(4,19,28,29)$.Time taken for causing larval death was more with isolates of $\mathrm{H}$. armigera origin as compared to isolates of S. litura origin. A similar variation in terms of susceptibility of $\mathrm{S}$. litura and $\mathrm{H}$. armigera origin to different geographical isolates of N. rileyi has been reported (34).

Among all ten N. rileyi isolates of S .litura and H. armigera origin, Dharwad and Bailhongal isolates of S. litura origin showed the highest percent mortality of 96.7 and $95 \%$, respectively, after ten days of post inoculation (Table 2). The lowest mortality ( $85 \%$ ) was recorded in the Bangalore isolate of $\mathrm{H}$. armigera origin (Table 3). Isolates of entomopathogenic fungi from different host insects have varying degrees of virulence as measured by percent mortality in bioassays $(13,15)$.The mortality of the third instars treated with $\mathrm{N}$. rileyi ranged from 85 to $96.7 \%$ at spore concentration of $1 \times 10^{8}$ spores $/ \mathrm{ml}, 10$ days after inoculation (Table 2 and Table 3). This is similar to the observation to others that N. rileyi was pathogenic to S. litura and other lepidopteran pests $(9,23,32,33,34)$. They observed the pathogenicity levels ranging from 70 to $100 \%$ in S. litura. However, in our research after ten days of spore inoculation, there was no significant difference among the isolates with respect to their insecticidal activity. This strongly suggests that the isolates from different geographical 
locations are equally pathogenic. This is in line with the observations of other researchers $(5,15,17,20,21)$ who observed similar insecticidal activity among the isolates obtained from different locations. The sequential stages of the larval death showing different symptoms are shown in Figure 4.

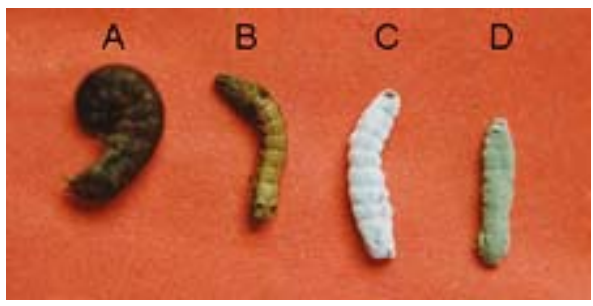

Fig. 4. Progress of infection of $\mathrm{N}$. rielyi on $\mathrm{S}$. litura: (A) healthy larvae (8 days old; (B) dead larvae (after 5 days of spore application); (C) dead larvae with thick white fungal hyphae (after 7 days of spore application); and (D) dead larvae covered with green colored conidia (after 10 days of spore application).

\section{Conclusion}

The most important criteria for commercial exploitation of any entomopathogenic fungus is its virulence against the target insect pest. High percent of mortality observed in this study, indicates the potential of N. rileyi isolates of S. litura and $\mathrm{H}$. armigera origin from different geographic locations for controlling S. litura. However, isolates of S. litura origin cause higher percent mortality and also take less time to cause larval death compared to isolates of $\mathrm{H}$. armigera origin. $\mathrm{N}$. rileyi isolates of Dharwad location followed by Devihosur are the most virulent isolates from our collection within 7 days after spore inoculation. However due to the observed high susceptibility of S. litura to $\mathrm{N}$. rileyi, all isolates of $\mathrm{N}$. rileyi from our collection can be used against $\mathrm{S}$. litura. Detailed studies about differences in conidial germination time, spore yields, ease and cost effective method of mass production, chitinolytic enzyme profiles, and optimum environmental conditions for infectivity have to be done to identify isolates with best traits for further exploitation as myco-insecticides. There is also a need to screen the pathogen against other insect pests to exploit its full potential. In addition, there is a need to assess their toxicity on nontarget insects.

\section{Acknowledgments}

We are grateful to Dr. S. Lingappa and Dr. G. K. Ramegowda of University of Agricultural Sciences, Dharwad, India, for providing the pure culture of S. litura for bioassay studies and also for providing isolates NR-B and NR-H. Dr. Jeong Jun Kim, Lethbridge Research Centre, Canada, and Mr. Mohankumar H. Kapanigowda, Texas A\&M University, College Station, TX, USA, for their advice on statistical analysis using SAS.

\section{Literature Cited}

1. Anand, R., Prasad, B., and Tiwary, B. N. 2009. Relative susceptibility of Spodoptera litura pupae to selected entomopathogenic fungi. BioControl 54:85-92.

2. Bell, J. V. 1975. Production and pathogenicity of the fungus Spicaria rileyi from solid and liquid media. J. Invertbr. Pathol. 26:129-130.

3. Boucias, D. G., Schoborg, E. A., and Allen, G. E. 1982. The relative susceptibility of six noctuid species to infection by Nomuraea rileyi isolated from Anticarsia gemmatalis. J. Invertbr. Pathol. 39:238-240.

4. Dayakar, S., and Kanaujia, K. R. 2003. Evaluation of the pathogenicity of Beauveria bassiana, Metarhizium anisopliae and Nomuraea rileyi on different larval stages of tobacco caterpillar, Spodoptera litura (F.). Indian J. Plant Prot. 31:2.

5. Fargues, J., and Miniania, N. K., 1992. Variation in the susceptibility of Spodoptera littoralis to the entomopathogenic hyphomycete Nomuraea rileyi. Entomophaga 37:545-554. 
6. Ferron, P. 1978. Biological control of insect pests by entomopathogenic fungi. Annu. Rev. Entomol. 23:409-442.

7. Gardner, W. A. 1985. Effect of temperature on the susceptibility of Heliothis zea larvae to Nomuraea rileyi. J. Invertbr. Pathol. 3:2-10.

8. Gillespie, A. T., and Moorhosue, E. R., 1981. The use of fungi to control pests of agricultural and horticultural importance. Pages 55-84 in: Biotechnology of Fungi for Improving Plant Growth, ed. J. M. Whipps and R. D. Lumsden, Cambridge Univ. P., Cambridge, UK.

9. Gopalkrishnan, C., and Narayanan, K., 1988. Occurrence of two entomofungal pathogens, Metarhizium anisopliae (Metschinkoff) sorokin var, minor Tulloch and Nomuraea rileyi on Heliothis armigera. Current Sci. 57:867-868.

10. Gupta, V. P. 2003. Natural occurrence of the entomopathogenic fungus Nomuraea rileyi in the soybean green semilooper, Chrysodeixis acuta, in India. Online. Plant Health Progress doi:10.1094/PHP-2003-0113-01-HN.

11. Ignoffo, C. M. 1981. The fungus Nomuraea rileyi as a microbial insecticide. Pages 513-538 in: Microbial Control of Pests and Plant Diseases, 1970-80 H. D. Burges, ed. Academic Press, London, UK.

12. Ignoffo, C. M., and Boucias, D. B. 1992. Relative activity of geographical isolates of Nomuraea bioassayed against the cabbage looper and velvetbean caterpillar. J. Invertbr. Pathol. 59:215-217.

13. Ignoffo, C. M., and Garcia, C. 1985. Host spectrum and relative virulence of an Ecuadoran and Mississipian biotype of Nomuraea rileyi. J. Invertbr. Pathol. 45:346-352.

14. Ignoffo, C. M., Garcia, C., and Samson, R. A. 1989. Relative virulence of Nomuraea spp. (N. rileyi, N. atypicola, N. anemonoides) originally isolated from an insect, a spider and soil. J. Invertbr. Pathol. 54:373-378.

15. Ignoffo, C. M., Puttler, B., Hostetter, D. L., and Dickerson, W. A., 1976. Susceptibility of the cabbage looper, Trichoplusia ni, and the velvetbean caterpillar, Anticarsia gemmatalis to several isolates of the entomopathogenic fungus Nomuraea rileyi. J. Invertbr. Pathol. 28:259-262.

16. Kiuchi, M., Yasui, H., Hayasaka, S., and Kamimura, M. 2003. Entomogenous fungus Nomuraea rileyi inhibits host insect molting by C22-oxidizing inactivation of hemolymph ecdysteroids. Archiv. Insect Biochem. Physiol. 52:35-44.

17. Lezama, G. R., Alatorre, R. R., Hernandez, J. L., and Gonazalez, H., 1993. In vitro sensitivity of fall armyworm larvae Spodoptera frugiperda to the fungi Paecilomyces fumoroseus and Nomuraea rileyi. Adv. Investig. Agropecuaria 2:90-99.

18. Liburd, O. E., Funderburk, J. E., and Olson, S. M. 2000. Effect of biological and chemical insecticides on Spodoptera species (lep., Noctuidae) and marketable yields of tomatoes. J. Appl. Entomol. 124:19-25.

19. Lin, H. F., Yang, X. J., Gao, Y. B., and Li, S. G. 2007. Pathogenicity of several fungal species on Spodoptera litura. Ying Yong Sheng Tai Xue Bao. 18:937-940.

20. Lopez-lastra, C. C., and Boucias, D. G. 1994. Studies on the cellular reactions of Spodoptera exigua larvae infected with the fungus Nomuraea rileyi. J. Invertbr. Pathol. 63:101-102.

21. Manjula, K., and Krishna Murthy, K. V. M. 2005. Efficacy of Nomuraea rileyi against different instars of Spodoptera litura and Helicoverpa armigera. Ann. Plant Prot. Sci. 13:2.

22. Mazier, M., Pannetier, C., Tourneur, J., Jouanin, L., and Giband, M. 1997. The expression of Bacillus thuringiensis toxin genes in plant cells. Biotechnology 3:313-347.

23. Rao, V. G., and Phadke, C. H. 1977. A Muscardine disease of tobacco leaf eating caterpillar. Current Sci. 46:648-649.

24. Roberts, D. W., and Hajek, A. E. 1992, Entomopathogenic fungi as bioinsecticides. Pages 144-159 in: Frontiers in Industrial Mycology. G. F. Letham, ed. Chapman and Hall, New York, NY.

25. Roberts, D. W., and Humber, R. A. 1981. Entomogenous fungi. Pages 201-236 in: The Biology of Conidial Fungi, Vol. 2. G. T. Cole and B. Kendrick, eds. Academic Press, New York, NY.

26. Roberts, D. W., and Hajek, A. E. 1992, Entomopathogenic fungi as bioinsecticides. Pages 144-159 in: Frontiers in Industrial Mycology. G. F. Letham, ed. Chapman and Hall, New York, NY.

27. Srisukchayakul, P., Wiwat, C., and Pantuwatana, S. 2005. Studies on the pathogenesis of the local isolates of Nomuraea rileyi against Spodoptera litura. ScienceAsia 31:273-276. 
28. Tang, L. C., and Hou, R. F. 1998. Potential application of the entomopathogenic fungus, Nomuraea rileyi, for control of the corn ear worm, Helicoverpa armigera, Entomol. Exper. et Appicata 88:25-30.

29. Tang, L. C., and Hou, R. F. 2001. Effects of environmental factors on virulence of entomopathogenic fungus Nomuraea rileyi against the corn earworm Helicoverpa armigera (lep., Noctuidae). J. Appl. Entomol. 125:243-248.

30. Tigano, M. S., Faria, M. R. De., Lecuona, R. E., Sartori, M. R., Arima, E. Y., Diaz, B. M., and De-faria, M. R. 1995. Analysis of pathogenicity and germination of the fungus Nomuraea rileyi isolated in Federal district. Anais da Sociedade Entomol. do Brasil 24:53-60.

31. Vargas, L. R. B., Rossato, M., Dasilva-ribeiro, R. T., and De-barros, N. M. 2003. Characterization of Nomuraea rileyi strains using polymorphic DNA, virulence, and enzyme activity. Brazil. Arch. Biol. Technol. 46:13-18.

32. Vimaladevi, P.S. 1994. Conidia production of the entomopathogenic fungus N. rileyi and its evaluation for control of Spodoptera litura on Ricinus communis. J. Invertbr. Pathol. 63:145-150.

33. Vimladevi, P. S., and Prasad, Y. G. 2001. Nomuraea rileyi: A potential mycoinsecticide. Pages 23-38 in: Biocontrol Potential and its Exploitation in Sustainable Agriculture, Vol. 2. Insect Pests. R. K. Upadyay, K. G. Mukherji, and B. P. Chamola, eds. Kluwer Academic/Plenum Publisher, New York, NY.

34. Vimala Devi, P. S., Prasad, Y. G., Chowdary, D. A., Mallikarjuna Rao, L., and Balakrishnan, K. 2003. Identification of virulent isolates of the entomopathogenic fungus Nomuraea rileyi (F.) Samson for the management of Helicoverpa Armigera and Spodoptera litura. Mycopathologia. 156:365-373. 